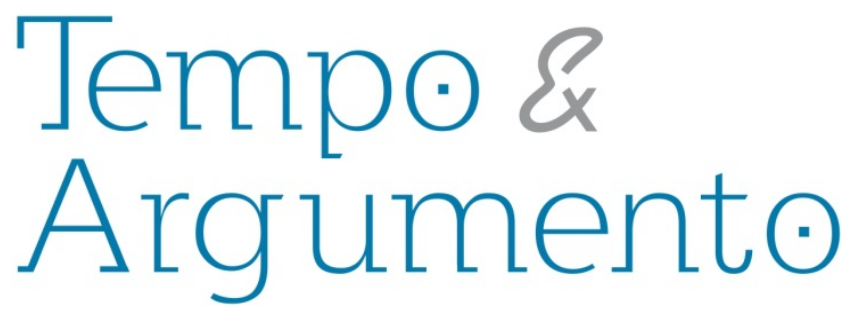

\title{
Os primeiros Congressos Americanos da Criança e a pan- americanização dos debates sobre a infância (1916 a 1922)
}

\begin{abstract}
Resumo
Nas primeiras décadas do século $X X$ passam a se reunir periodicamente, em diferentes países da América Latina, autoridades políticas, especialistas e filantropos interessados em debater as questões da infância americana. O papel simbólico da infância na modernização da América, a educação da criança como motor do desenvolvimento das nações e do continente, em debate nos primeiros Congressos Americanos da Criança (1916-1922), são o cerne deste artigo.
\end{abstract}

Palavras-chave: Infância - História; Educação - America Latina - História; Criança - Congressos.

\section{Gizele de Souza}

Doutora em Educação pela Universidade Católica de São Paulo. Pós-doutorado pela Università degli Studi di Firenze/Itália.

Professora do Programa de Pós-Graduação em Educação da Universidade Federal do Paraná. Coordenadora do Núcleo de Estudos e Pesquisas em Infância e Educação Infantil. Brasil gizelesouza@ufpr.br

\section{Andréa Cordeiro}

Doutora em Educação pela Universidade Federal do Paraná. Pesquisadora do Núcleo de Estudos e Pesquisas em Infância e Educação Infantil. Brasil cordeiroandrea@yahoo.com.br

\section{Para citar este artigo:}

SOUZA, Gizele de; CORDEIRO, Andréa. Os primeiros Congressos Americanos da Criança e a panamericanização dos debates sobre a infância (1916 a 1922). Revista Tempo e Argumento, Florianópolis, v. 7, n.14, p. 05 - 28. jan./abr. 2015.

\section{DOI: $10.5965 / 2175180307142015005$}

http://dx.doi.org/10.5965/2175180307142015005

\footnotetext{
${ }^{1} \mathrm{~A}$ análise dos congressos debatidos no presente artigo encontra-se aprofundada na tese realizada com fomento CAPES (PDSE): CORDEIRO, Andréa. Luz e Caminho aos pequenos. Os primeiros congressos americanos da criança e a pan-americanização dos saberes sobre a infância (1916-1922). 2015. Tese (Doutorado em Educação). UFPR, Curitiba. 2015.
} 


\title{
The first American Child \\ Congresses and the pan- americanization of debates around childhood (1916 to 1922)
}

\begin{abstract}
In the first decades of the twentieth century, political authorities, experts and philanthropists, start to meet periodically in different Latin American countries, interested in discussing the issues of American childhood. The symbolic role of childhood in the modernization of America, the child's education as an engine for development of nations and the continent, in debate in the first American Congresses of the Child (1916-1922), are at the core of this paper.
\end{abstract}

Keywords: History of Childhood; History of Education; Latin America; American Congresses of Child.

O propósito deste trabalho é refletir sobre alguns aspectos da pan-americanização dos debates sobre a infância, no período de 1916 a 1922, tendo por referência fontes vinculadas aos primeiros Congresos Americanos del Niño, cujas primeiras edições ocorreram entre os anos de 1916 e 1922.

Analisaremos algumas nuances do movimento pela unificação da América, e, sobretudo, da América Latina no início do século XX por meio do exame de discursos e proposições carregadas de representações sobre as relações científico-políticas acerca da infância, seu governo, sua proteção e educação. 
O primeiro destes congressos americanos da criança realizou-se no ano de 1916, em Buenos Aires, fruto direto do "Primer Congreso Nacional Del Niño" realizado em 12 de outubro de 1913 em Tucumã- Argentina, sob a organização da Liga para los Derechos de La Mujer y El Niño.

Este primeiro Primer Congreso Americano del Niño compôs a extensa agenda de congressos e exposições nas festividades do Centenário da Independência Argentina em julho de 1916 e, sob a coordenação da mesma liga de mulheres socialistas, presidida pela médica Julieta Lanteri, contou com a participação de aproximadamente 200 inscritos de 13 países. Neste evento, lançam-se as bases $^{2}$ para o que virá a ser uma longeva tradição de congressos interamericanos para a discussão da infância, realizados em diferentes países da América Latina e nos Estados Unidos.

O Segundo Congreso Americano del Niño teve lugar em Montevidéu, no Uruguai, no ano de 1919. O médico pediatra Luis Morquio, nome de grande prestígio científico na América Latina à época, presidiu este evento, que teve seus documentos, textos originais de participantes e demais fontes cuidadosamente preservados pelo governo uruguaio, convertendo-se num manancial de pesquisa promissor. O segundo congresso contou com a participação de aproximadamente 1.100 pessoas, de 16 países.

O Terceiro Congresso Americano da Criança, cuja realização foi inicialmente prevista para 1920, no Rio de Janeiro, Brasil, sofreu diversos adiamentos por força de entraves burocráticos e financeiros, sendo finalmente realizado em concomitância com o Primeiro Congresso Brasileiro de Proteção à Infância, o que conferiu ao evento a adesão de aproximadamente 2.700 pessoas de 16 países. Este Congresso Americano da Criança foi igualmente presidido por um pediatra: Olympio Olinto de Oliveira, co-fundador da Sociedade Brasileira de Pediatria. O número elevado de participantes se deve também ao fato de que os inscritos em ambos os eventos foram agrupados e as seções dos congressos se realizaram em conjunto. Este congresso também veio a lume numa festividade de jubileu: O Centenário da Independência do Brasil.

\footnotetext{
${ }^{2}$ Tais bases dizem respeito a aspectos estruturais que serão mantidos por longos anos na tradição destes congressos, dentre os quais destacamos o elemento da multiplicidade de temas em debate, divididos por seções temáticas, a emissão de conclusões sob a forma de votos finais em uma sessão na qual os votos das principais conclusões de cada seção temática são levadas a conhecimento de todos e a escolha do próximo país sede em uma sessão de encerramento.
} 
O fato de todos os presidentes dos primeiros congressos americanos da criança serem médicos logicamente não é acidental e relaciona-se com a preponderância da área médica nas searas pioneiras da infância como objeto de estudo, pesquisa e ação. Olinto de Oliveira, Luis Morquio e Julieta Lanteri, além de médicos mantinham, com suas particularidades, forte atuação política e vinculação aos grupos mobilizados em torno da proteção e assistência à infância.

A escolha - ainda que por contingências, como no caso do congresso de 1922 - de uma data de efeméride cívica como um Centenário para potencializar a realização dos congressos é relevante, pois o ensejo do aniversário comemorativo, que Hobsbawm destaca como momento de grande força publicitária para a nação (1987, p. 288) é também um momento de balanço, de recuperação das promessas da independência, de encontro com as realidades nacionais (MOTTAS, 1992) e de se dar a ver em suas conquistas aos convidados de outros países. No contexto dos congressos americanos da criança, é a oportunidade de levar a público as preocupações das nações para com as questões da infância, numa franca demonstração de desejos de progresso e prosperidade, uma vez que preocupar-se com a infância e traçar projetos políticos e científicos visando sua proteção, assistência e educação passará a ser um sinal de modernidade e compromisso para com o futuro.

Assim como as Exposições Universais, bastante tematizadas na historiografia, os congressos, realizados em profusão entre finais do século XIX e inicio do XX, tornaram-se espaços especialmente estratégicos para as Nações modernas propagandearem sua adesão aos avanços científicos e tecnológicos através da exemplaridade e da espetacularização (PESAVENTO, 1997).

No caso dos Congressos da Criança, era a oportunidade que encontravam os envolvidos com a temática da infância em suas diversas faces (pediatras, professores, juristas, políticos, filantropos) para colocar luzes sobre a importância estratégica da infância em um projeto com pretensão de progresso e modernidade.

A responsabilidade de representar seu país, destacando os avanços e projetos em prol do atendimento da infância, fica patente no conteúdo de grande parte dos discursos dos representantes oficiais das delegações estrangeiras nas aberturas e encerramentos 
destes eventos. Atestando este sentimento de compromisso propagandístico que envolvia as delegações participantes, vejamos o que diz Henrique Paz Soldan, pediatra peruano delegado oficial do Peru sobre sua participação em vários congressos da criança:

(...) como delegado oficial do Peru, nos Congressos Pan Americanos da Criança, participei carregando sempre na bagagem o meu amor ardente pela glória e prestígio da pátria. Não falei neles mais do que eu deveria falar. E naquelas Assembleias de otimismo continental, procurei fazer de meu verbo clarim vibrante fazendo apologia de tudo de bom que tínhamos realizado em casa. Jamais naquelas ocasiões fiz censuras ou pronunciei condenações ao peruano, o que sempre pensei ser meu dever de reservar para uso doméstico. ."(PAZ SOLDAN, 1944, p. 9) ${ }^{3}$

Esta citação de Paz Soldan foi publicada em uma coletânea de textos realizada pelo autor na década de 1940 no Peru, na qual a primeira parte é dedicada aos discursos e trabalhos que apresentou nestes eventos, dos quais participou de cinco edições entre 1922 e 1935. O congressista deixa claro que os encontros eram um momento otimista para mostrar resultados, partilhar êxitos, estabelecer relações diplomáticas cordiais.

No entanto, se por este viés podemos pensar, com Walter Benjamin (1985) e Pesavento, nos congressos como espaço para a fantasmagoria, onde se estava "mostrando o que deve ser mostrado, travestindo a realidade e ocultando o que é possível ser ocultado" (PESAVENTO, 2004, p. 25) teremos nas demais fontes destes encontros a oportunidade de encontrar alguns contrapontos aos discursos laudatórios, pois participarão com trabalhos nas diferentes seções pessoas envolvidas de formas variadas com as questões da infância: serão diretores de escola, psicólogos, professores, inspetores de ensino, médicos, religiosos, feministas, damas de caridade, militares e anarquistas, todos de alguma maneira trazendo aos encontros suas contribuições na forma de relatos de experiência, de propostas de projetos, de reivindicações e anseios.

\footnotetext{
3 “como delegado oficial del Perú, en los Congresos Panamericanos del Niño , a los que asistí, llevando siempre como bagaje mi ardiente amor por la gloria y el prestigio de la patria. No hable en ellos más de lo que debía hablar. $Y$ en esas Asambleas de optimismo continental, mi verbo procuré que fuera clarinada vibrante haciendo la apología de cuanto de bueno habíamos realizado en casa. Jamás en esas ocasiones hice censuras, ni pronuncié condenaciones de lo peruano, las que siempre creí deber mío reservar para uso doméstico- Tradução nossa.
} 
Essa diversidade de elementos marca o diferencial dos Congressos Americanos da Criança, por não se constituírem um foro de uma especialidade única como ocorria com congressos exclusivamente dedicados à higiene, à educação, aos tribunais de menores, por exemplo. A multiplicidade de áreas em debate contribuiu para que fossem um manancial interessante para pesquisas, considerando que abarcam uma miríade de possibilidades para a circulação de ideias, expressão de representações sobre a infância, e também de lutas de representação sobre projetos de Estado e ações de assistência e escolarização da infância

Os Congresos Americanos del Niño - que a partir de sua quarta edição, em 1924, em Santiago do Chile, passam a se chamar Congresos Panamericanos Del Niño - atravessaram o século $X X$ e adentraram o XXI, tendo a mais recente de suas edições (XXI Congreso Panamericano del niño, la niña y adolescentes) ocorrido em dezembro 2014, em Brasília, Brasil. As discussões que levantaremos nesse texto estarão circunscritas às três primeiras edições dos eventos acima mencionados.

No recorte ora trazido a lume, propomo-nos a discutir a infância enquanto território de tensão entre futuro e tradição, a infância como um dos símbolos da unidade pan-americana e alguns aspectos sobre os debates acerca da educação da criança travados nestes encontros.

\section{A infância, presente e futuro}

As discussões acerca da infância travadas naquele início de século XX estarão atreladas a uma noção de porvir que excede as circunstâncias presentes das experiências das crianças reais que crescem na América do período, projetando estas experiências para suas consequências ao futuro das nações (CARLI, 2003).

Assim, medidas que visarão proteger e assistir às crianças e suas famílias, promovendo uma melhora na sua segurança e bem estar se entretecerão às que se produzirão no intento de ampliar a vigilância, punição e controle das crianças, sobretudo das pobres, à potencial ameaça que estas representavam aos processos de progresso e modernização das nações. Em ambos os casos, a ideia de futuro enlaçada à de criança parece ser um grande motor das ações em prol da infância neste início de século. 
A criança pobre, mal nutrida, perambulando solta pelas ruas da cidade escapava ao projeto de ordem e progresso tão desejado. O ordenamento e saneamento da cidade, bem como a prosperidade da nação e do continente dependiam em muito do controle da população pobre e as crianças eram parcela decisiva deste grupo potencialmente compreendido como perigoso.

A força com que os discursos moralizantes e saneadores se lançam sobre as famílias pobres e suas crianças, mesclados a notas emotivas e piedosas revela muito mais do que um movimento estudado, positivista e racional em direção a um projeto de sociedade que deveria se cumprir para que as Nações latino-americanas seguissem os rumos do progresso, revela também os temores que circundavam o Estado e as elites em relação à potencial ameaça representada pelos pobres e por toda sorte de "outsiders", a criança inclusive, que não se ajustassem aos novos e modernos tempos.

Controlar "instintos", educar e restringir os movimentos, modificar os hábitos, limitar os trajetos e regrar os tempos destes pretensos perigosos e espontâneos indivíduos se torna então um imperativo para que um modelo de sociedade limpa e funcional de fato se viabilize. A infância, como a pobreza sem o controle do Estado, fraturam este paradigma.

O paralelo entre infância e pobreza perpassará literalmente alguns trabalhos de congressistas destes três primeiros Congresos del Niño:

Diz Maxwell que o próprio Montesquieu já falava no Espirit dos lois: 'Algumas esmolas que deram na rua a um homem nú, não supprem as obrigações do Estado, que deve a todos os cidadãos uma assistência assegurada, a comida, um facto conveniente e um gênero de vida que não seja contrária à saúde". Maximé isso se deduz, quando se trata da saúde physica, moral e material da criança que representa o futuro 'prosperidade e progresso do Estado, sob os pontos de vista intelectual, moral e material' (...) Ninguém melhor que o Estado, nas circunstancias em que nos debatemos, é capaz de assumir o peso de tais responsabilidades, tratando-se como se vê de uma necessidade pública em que ele é o maior interessado. Questão toda prática, trata-se de garantir o numero de braços para o trabalho, a fim de aumentar a fortuna comum. (SOBRAL, 1922, p.304)

\footnotetext{
${ }^{4}$ A ideia de outsider aqui remete a uma das faces do herói moderno de Baudelaire (Benjamin, 2006), o homem solitário e comum que tenta sobreviver na constante situação de conflito gerada pelas contradições e belezas da modernidade, sem conseguir, no entanto, se enquadrar ao ideal de homem moderno, industrioso, consumidor, racional.
} 
No recorte acima, extraído do trabalho apresentado pelo brasileiro Francisco Sobral no Terceiro Congresso Americano da Criança e Primeiro Congresso Brasileiro de Proteção à Infância,é nítida a aproximação entre a infância e a pobreza, tomadas como equivalentes. A citação também trará um elemento essencial para entendermos as representações e ações sobre a infância no período, pois deixará patente a necessidade da forte ação tutelar do Estado sobre a infância. Ao Estado, para seu próprio bem e para o progresso geral, caberia assumir a assistência aos pobres e às crianças, sob o risco de que se não o fizesse faltassem braços para o trabalho e sustento da própria engrenagem estatal. Tal perspectiva é debatida por outros estudos sobre a infância referente ao contexto do início do século XX. Irene Rizinni, ao analisar as intervenções estatais sobre as crianças "moral e materialmente abandonadas", afirma:

A intervenção do Estado junto a esse segmento da infância era defendida como uma ampla 'missão saneadora, patriótica e civilizatória' em prol da reforma do Brasil. A missão era idealizada como parte do projeto de construção nacional desde os primeiros anos de instauração do regime republicano. O discurso predominante continha uma ameaça implícita - a de que o país seria tomado pela desordem e pela falta de moralidade, se mantivesse a atitude de descaso em relação ao estado de abandono da população, em particular a infância. (RIZZINI, 2006)

Em se tratando dos demais países da América e América Latina, a partir das fontes dos Congressos da Criança, a situação de pressão quanto à ação do Estado sobre a infância pobre não era muito diferente, pois embora com ritmos um pouco diversos, todas as nações latino-americanas estavam de certa forma vivendo este momento de projeto de modernização, de necessidade de fortalecimento político interno, de recrudescimento dos problemas sociais em razão direta à ampliação das cidades e das mudanças nas relações de trabalho e convívio social. Sobre esta necessidade americana de valorizar a infância e sua proteção, diz o delegado argentino no seu discurso na cerimônia de abertura do Segundo Congreso Americano del Niño:

Uma evolução justíssima e de grandes resultados esta sendo operada no espírito público dos países civilizados. As gerações que nos precederam amaram a criança, ser de fragilidade e frescor, somente pelo encanto e 
alegria que ela trazia ao lar. Nos tempos contemporâneos esta bela sentimentalidade subsiste sempre vivaz, porém ela se acompanha de preocupações positivamente utilitárias. A criança aparece, sobretudo, como um capital precioso que ha que se conservar e aumentar para assegurar a saúde e a força das nações. E esta preocupação é tanto mais justa e explicável em nossos jovens países americanos, pois somos todos, mais ou menos, povos em formação, com extensos territórios que povoar, com grandes riquezas naturais que valorizar $(\ldots) .^{5}$

Para Araoz Alfaro, as representações da criança em sua pureza e fragilidade permanecerão, mas como coadjuvantes, cedendo espaço à ideia da criança como capital para o futuro. Além disso, Alfaro, ao afirmar que a criança não era mais enxergada apenas como a alegria do lar, sinaliza uma tendência emergente neste inicio de século: a paulatina homogeneização da infância pela via de sua escolarização e normatização, e, com esta possibilidade de intervenção estatal sobre a criança, ela passa a se configurar como "um sujeito que extrapolava os núcleos familiares e os setores sociais de origem, devendo inscrever-se em uma ordem pública" (CARLI, 2003, p. 37).

Esta premissa será fundamental nos debates acerca das mudanças em relação ao pátrio poder, do abandono dos filhos, das questões da legitimidade dos filhos e dos limites da intervenção estatal sobre as famílias, "célula ao redor da qual se agrupa toda a organização social”, segundo diz o uruguaio Luis Morquio na abertura do Segundo Congreso del Niño. Na continuidade de seu discurso, Morquio afirmará que se a família, que deveria ser a base de "solidez indispensável à criança", agir em prejuízo da mesma “corresponderá ao Estado, por intermédio de suas instituições especiais proteger este ser desgraçado" (MORQUIO, 919, p. 90).

\footnotetext{
${ }^{5}$ Una evolución justísima y de grandes resultados se ha operado en el espíritu público de los países civilizados. Las generaciones que nos precedieron han amado al niño, ser de debilidad y de frescura, solo por el encanto y la alegría que él aportaba al hogar. En nuestros contemporáneos esa hermosa sentimentalidad subsiste siempre vivaz, pero ella se acompaña de preocupaciones positivamente utilitarias. El niño aparece, sobre todo como un capital precioso que hay que conservar y aumentar para asegurar la salud y la fuerza de las naciones. $Y$ esa preocupación es tanto mas justa y explicable en nuestros jóvenes países americanos cuanto somos todos, más o menos, pueblos en formación, con extensos territorios que poblar, con grandes riquezas naturales que poner en valor (...). (ARAOZ ALFARO, Segundo Congreso Americano del Niño, Tomo Primeiro, 1919, p.96)
} 


\section{Relações internacionais e as possibilidades de afirmação americana no contexto da Primeira Guerra Mundial}

Os Congresos Americanos del Niño se configurarão como espaço de intensos debates, em um cenário marcado pela promessa de futuro representada pela América ante à desilusão, ao menos no campo discursivo perceptíveis nos congressos em estudo, frente à Europa, cujo prestígio no campo das relações internacionais decai em consequência da Primeira Grande Guerra, deixando as nações americanas na condição de críticas, dispostas a assumirem seu quinhão de liderança.

Cezar Sanches Aizcorbe, delegado da comitiva peruana no Segundo Congreso Americano del Niño (Montevidéu, 1919), assim se manifesta em discurso na solenidade de abertura do evento:

Depois desta guerra global, este grande salto para trás, deste retrocesso à barbárie não é mais possível, senhores, persistir no erro que tantas lágrimas e tanto sangue custou à humanidade. Reconheçamos, pois, ainda que este reconhecimento possa ferir muitos preconceitos e interesses valiosos criados. Toda dissecação, exceto em um cadáver, tem que ser dolorosa. E eu já vos disse. América, a América nossa, a Atlântida sonhada pelos poetas e deduzida como uma necessidade de equilíbrio geográfico pelos sábios do mundo antigo é a nossa esperança para a Humanidade. A ela, a nós, aos homens de nossa geração corresponde, por um verdadeiro mandato histórico, dirigir após o cataclismo a obra da reconstrução. Invistamos nisto com plena consciência de nossos inexcusáveis deveres e de nossos grandiosos destinos. Salvemos, com o pensamento e com o coração nossas fronteiras politicas, para formar a alma coletiva americana, que será a alma da humanidade. ${ }^{6}$

E a formação desta alma americana será em grande medida tomada pelos sujeitos envolvidos com a crescente causa da infância como equivalente à formação da infância numa perspectiva geracional. A criança se torna, neste contexto, a personificação desta

\footnotetext{
${ }^{6}$ Después de esta guerra mundial, de este gran salto atrás, de este retroceso a la barbarie, ya no es posible, señores, persistir en el error que tantas lágrimas y tanta sangre han costado a la humanidad. (...) América, la américa nuestra, esta Atlántida soñada por los poetas y deducida como una necesidad de equilibrio geográfico por los sabios del mundo antiguo, es la nuestra esperanza de la humanidad. A ella, a nosotros, a los hombres de nuestra generación corresponde por un verdadero mandato histórico, dirigir después del cataclismo la gran obra reconstructiva. Acometámosla con plena consciencia de nuestros inexcusables deberes y de nuestros grandiosos destinos. Salvemos, con el pensamiento, y con el corazón nuestras fronteras políticas, para formar el alma colectiva americana, que será el alma de la humanidad. (AIZCORBE, Cezar Sanches, Segundo Congreso Americano Del Niño, Tomo Primeiro,1919, Montevidéu, p. 127).
} 
Neste sentido, se “desborda la cuestión del niño como sujeto y se proyecta sobre las transformaciones de la sociedad como totalidad, y que indica su articulación con la emergencia de los imaginarios sociales acerca de las nuevas generaciones" (CARLI, 2003, p. 27). A infância que é objeto dos discursos destes congressos, é então entendida como terreno de constituição das crianças, mas também de modulação da sociedade e das gerações adultas futuras (CARLI, 2003, p. 15).

O discurso sobre a infância está inscrito, pois, nesta tensão entre tradição, presente e futuro e, neste contexto, é possível visualizar a representação da ideia de manutenção e aperfeiçoamento da própria modernidade e da América como continente forte.

Percebamos como as imagens de passado, futuro, esperança, oferenda, amor aparecem todas encadeadas à ideia de criança em um pequeno fragmento do discurso do Ministro de Instruccion del Uruguay, Rodolfo Mezzera, na sessão solene inaugural do Segundo Congreso del Niño - 1919. Este discurso foi pronunciado pelo ministro no mesmo dia do funeral de sua mãe e faz menção às coroas de rosas e outros tributos deixados sobre os túmulos em honra da memória dos falecidos:

Penso - no entanto, que seria muito melhor, que teria um significado mais amplo e impacto mais eficaz oferendar para aqueles que se foram na honra e no bem, - na forma de uma insigne recompensa - o canto alegre das crianças, que levam em cada sorriso uma esperança e a cada mecha de cabelo uma incógnita e em cada olhar e cada grito e cada gesto o belo germe do bem e do amor. Não pode haver maior oferenda desde que é a infância um belo símbolo que com os elementos do passado constrói e desenvolve o futuro.?

\footnotetext{
7 Pienso - sin embargo- que seria mucho mejor, que tendría un más alto significado y una repercusión más efectiva ofrendar a los que se fueran en el honor y ele bien, - a la manera de una insigne recompensa, -con los cantos alegres y bulliciosos de los niños, que llevan en cada sonrisa una esperanza, y en cada guedeja una incógnita, y en cada mirada y en cada grito y en cada gesto el germen hermoso del bien e del amor. No puede haber ofrenda superior desde que la niñez es un hermoso símbolo que con los elementos del pasado construye y desarrolla el porvenir. MEZZERA, Rodolfo, Segundo Congreso Americano del Niño, Tomo primero, Montevideo, 1919, p. 73.
} 
A infância é tomada nesta citação num dos sentidos mais recorrentes desde o oitocentos: símbolo da pureza, equiparada às plantas - metáfora usada por inúmeros escritores, espraiada principalmente por meio da obra de Rousseau. "Amanham-se as plantas pela cultura e os homens pela educação" (ROUSSEAU, 1979, p. 10), esta máxima representa muito bem a ambiguidade dos sentidos dados à infância, que tanto poderia ser boa e pura, como por outro lado, selvagem e carente de condução, regramento e ordem pela via da educação.

Nesta perspectiva, temos a representação da infância e criança como esperança de uma humanidade renovada e civilizada convivendo nos congressos, não em desarmonia ou como contraponto à ideia menos romântica e mais pragmática da criança como capital de investimento para o futuro. Estas representações encontraram no início do século XX um cenário real um tanto duro e as crianças, sobretudo as crianças pobres, serão muitas vezes associadas, segundo as fontes examinadas, como resíduo mais evidente de uma população considerada doentia, ignorante e degenerada.

Tal dualidade reflete também os conflitos de uma identidade americana que tenta se inscrever como possibilidade de futuro ante às brechas abertas pela fragilidade da Europa no período da Primeira Guerra. "Situação política, passional existencial a guerra é um acontecimento em instância que "desmultiplica” os sentimentos ao mesmo tempo em que obriga os seres humanos a se tornarem diferentes daquilo que queriam ou imaginavam ser." (FARGE, 2011, p. 47).

Alterando profundamente a economia, a política e a diplomacia internacional, com a Primeira Guerra Mundial não mudam apenas as regras, "amplia-se o tabuleiro", como bem o diz Hobsbawm (1988, p. 434) e para a América, em alguns aspectos, a Guerra pareceu trazer a oportunidade de participação mais efetiva do jogo mundial das relações internacionais, além de oferecer uma possibilidade de maior afirmação de sua maioridade política e intelectual.

A guerra e a crise europeia estarão presentes em diferentes comunicações apresentadas nestes congressos. Além de constituírem a temática principal dos trabalhos norte americanos levados a estes eventos ${ }^{8}$ - que focarão principalmente na descrição dos

\footnotetext{
${ }^{8}$ Sobretudo os trabalhos das delegações dos Estados Unidos no Segundo Congresso Americano del Niño,
} 
projetos de proteção à infância norte americana encabeçados pelo Children's Bureau em tempos de guerra, o conflito mundial será mencionado em várias introduções de discursos dos participantes; a tônica destas menções é a de um pesar com toques de uma triunfante censura à Europa ${ }^{9}$, “donde o sangue de seus melhores filhos corre como água e a obsessão pela luta faz esquecer toda visão de futuro"10.

As falas de congressistas em diversos trabalhos nos três primeiros congressos revelam a busca de afirmação, também pela negação do que de selvagem e errático existe na natureza (e na criança) para o enaltecimento do que de belo, puro e aperfeiçoável há na América e nos pequenos americanos.

América, depois deste horrível massacre que desintegrou, que deslocou a hegemonia da Europa, está conclamada a ser para o mundo novo o que foi a Grécia para as idades remotas da humanidade: o berço da civilização. A nós nos incumbe agora fazer com que este berço seja de ouro, luzes e pedrarias, como aqueles dos contos de fadas cheios de idealismos que encantaram nossa infância, ou de bruta madeira, como os berços em que descansam os filhos de aldeões grosseiros. De nada valeriam as heroicas façanhas de Cristóvão Colombo se, seus audazes companheiros e valorosos continuadores se a América continuar sendo um solo fantástico, uma débil promessa de civilização em vez de ser uma realidade tangível imensamente produtora, poderosamente regeneradora. ${ }^{11}$

Com este parágrafo grandiloquente, o professor uruguaio Virgílio Cutinella inicia seu texto no qual propõe as bases do ensino do pan-americanismo na escola primária em todos os países americanos. Percebamos: a América sonhada e aqui expressa é uma superação de sua natureza, é a civilização e a riqueza em detrimento das rudes origens de

1919, Montevidéu.

${ }^{9}$ Entendemos que uma questão que mereceria um estudo mais aprofundado remete ao debate acerca da tensão entre América e Europa, mas também sobre a própria ideia do que se constituiu nomear de velho continente a Europa. E Bronislaw Geremek na obra “Le radici comuni dell'Europa", publicado em italiano em 1991, oferece um bom caminho reflexivo sobre isso.

${ }^{10}$ Segundo Congreso Americano del Niño, 1919, Antecedentes y organización. p. 65.

${ }^{11}$ América, después de esta horrible masacre que ha desintegrado, que ha dislocado la hegemonía de Europa, está llamada a ser para el mundo nuevo lo que fue la Grecia para las edades remotas de la humanidad: la cuña de la civilización. A nosotros nos incumbe ahora hacer con que esa cuna sea de oro, luces e pedrería, como aquellas de los cuentos de hadas, llenos de idealismos que encantaran nuestra niñez, o de burda madera, como en la que se descansan de los hijos de los aldeanos groseros. De nada valdrían las heroicas hazañas de Cristóbal Colón, sus audaces compañeros y valerosos continuadores, si la América continuara siendo un suelo fantástico, una débil promesa de civilización en vez de ser una realidad tangible, inmensamente productora, poderosamente regeneradora. CUTINELLA, Virgilio. Segundo Congreso Americano del Niño, 1919, p. 14. 
sua terra e sua população. Não é fato desimportante que nos muitos registros destes primeiros congressos que pudemos analisar não tenhamos encontrado menção às crianças de origens indígenas ${ }^{12}$ ou africanas. A criança americana que se espera burilar e que superará a dependência colonial é, paradoxalmente, de ascendência europeia.

O texto de Cutinella, que traz como epígrafe a sentença: "Debemos cimentar el porvenir futuro de América desde los bancos de la escuela. Esperemos de ellos la gran reforma continental," (p.14) é um dentre muitos sobre o tema da integração e fortificação da identidade americana levados ao debate nestes três congressos, demonstrando que a perspectiva da integração dos países americanos seria cara aos intelectuais da época e que a escolarização é tomada como o grande projeto regenerador do continente.

\section{A educação da criança americana: antes de crianças sábias, crianças boas}

A imagem do "cimento" usada pelo professor uruguaio e congressista Virgilio Cutinella é prenhe de significados. O cimento como metáfora da coesão será associado à escola e aparecerá em muitas menções dentro dos primeiros congresos americanos del niño, como em um dos trabalhos do médico, conselheiro escolar e político argentino Genaro Giacobini:

A vida espiritual nos países americanos, cimentada sobre o alicerce moral que a explica e define, (...) tem na escola, alvorecer da infância que se educa e bate asas em seu primeiro voo intelectual, a semente da sua obra social construtiva do aperfeiçoamento ético.13

A imagem do "cimento" será também evocada contemporaneamente por OSSENBACH (1993) quando discute os esforços pela unificação interna das nações latino

\footnotetext{
${ }^{12}$ Há apenas um relatório sobre a infância indígena, presente no Primeiro Congresso Americano del Niño, de autoria e de caráter antropológico, com descrição de hábitos e aspectos gerais da infância indígena. A partir do Quarto Congresso Panamericano del Niño, a temática parece ter sido mais presente nos debates.

${ }^{13}$ La vida espiritual en los países americanos cimentada en el fundamento moral que la explica y define que hace de su historia y vive en la ley de su desenvolvimiento, tiene en la escuela, albor de la niñez que se educa y aletea sus primeros vuelos intelectuales, la simiente de su obra social constructiva y de perfeccionamiento ético. GIACOBINI, Genaro. Segundo Congreso Americano del Niño, Secção Sociologia e Direito, tomo 13,1919, Montevideo, p. 3.
} 
americanas, pela via educativa, que se deram, segundo ela, sob o estabelecimento de um Estado de base oligárquica muito mais centralizador e ativo do que a maioria dos Estados liberais das nações europeias ${ }^{14}$. Ossenbach chamará a atenção sobre este aspecto significativo dos processos de modernização e escolarização na América Latina que, diferentemente do que se passou na Europa, não serão encabeçados por uma burguesia já consolidada e que atua como catalizadora de mudanças:

No capitalismo tardio que opera na América Latina (...) só a partir da esfera do Estado parecia possível unir as tramas abertas do tecido social. Desde o início do período independente foi preciso encarar o fenômeno da coexistência de várias sociedades dentro de um país, e ante essa fragmentação e desintegração socioeconômica o Estado deve garantir não só a unidade territorial-administrativa, mas também garantir a dinâmica econômica, a representação política e o "cimento" ideológico que dá liga e une as forças centrífugas. (OSSENBACH, 1993, p. 95)15

E será notadamente na escola que este "cimento ideológico" coesivo será trabalhado, assumindo o ensino uma função fortemente simbólica em relação aos valores sociais e morais, condutas e modelos de cidadãos e cidadãs a serem difundidos na sociedade.

Será papel do Estado assumir a tarefa da difusão e controle da escolarização como ferramenta de unificação, de coesão e de civilização da população em prol do desenvolvimento das nações. A defesa de um Estado que intervém fortemente e toma para si a responsabilidade pela educação das crianças aparecerá em diferentes momentos nos trabalhos apresentados nos congressos em estudo, como nesta fala do argentino

\footnotetext{
${ }^{14}$ Los nuevos Estados americanos iniciaban procesos muy acelerados de modernización, en los que el Estado adquirió un protagonismo muy destacado que parecía ser la única posibilidad de crear un orden nuevo. Si en Europa el liberalismo proclamó en muchos sectores la necesidad de que el Estado se abstuviera de intervenir en la sociedad, en Iberoamérica el factor político tuvo un peso más significativo que en otras regiones, porque aquí la consolidación del Estado constituía un prerrequisito esencial. (Ossenbach, 1993, p.95)

${ }^{15}$ En el capitalismo tardío que se desenvuelve en América Latina, por el contrario, sólo desde la esfera estatal parecía posible cohesionar los profundos desgarramientos del tejido social. Desde el inicio del período independiente se debió encarar el fenómeno de la coexistencia de varias sociedades en el interior de un país, y ante tal fragmentación y disgregación socioeconómica el Estado debía asegurar no sólo la unidad territorial-administrativa, sino procurar igualmente la dinámica económica, la representación política y el "cemento" ideológico que vincula y reune las fuerzas.
} 
José Gil Navarro apresentada na seção de Ensenanza do Segundo Congreso Americano del Niño:

O homem é um eu individual, a cujo encargo está a administração e uso de seu capital, a direção de suas ações e a prática da sua profissão. Mas como o produto do capital, o princípio da ação e o tipo da ocupação não são os mesmos (...) é preciso outro eu que canalize e abarque todas essas atividades e que nos represente a todos, colocando mais ênfase na unidade dessa grande variedade (...) este é o eu social: o Estado; esta é a sua missão e nele estão compreendidos os poderes que nós, geral e particularmente, exercendo nossa soberania lhe outorgamos. Se é verdade que este é o verdadeiro conceito da entidade chamada Estado é evidente que a ele corresponde a obrigação de prover a educação e instrução do povo, garantindo assim o cumprimento de um direito justamente reivindicado pela sociedade. ${ }^{16}$ (Grifos no original)

Na citação acima, a síntese da ideia que, fomentada no Sec. XIX, irá progressivamente adentrar o século XX na América Latina: o direito à educação, garantido pelo Estado, direito este que se desdobrará em um dever do cidadão frente à obrigatoriedade escolar que será paulatinamente instituída em diferentes nações do continente. A continuação do trabalho apresentado por Navarro indica esta preocupação: segundo o autor, o Estado não apenas deveria ofertar o ensino, mas garantir que todas as famílias fossem obrigadas a enviar suas crianças para a escola, sem que nenhum “pretexto da autoridade paterna” as mantivesse de fora, afinal, segundo o congressista:

Não é só o interesse da criança que está em jogo aqui, é o interesse da sociedade, exigindo com todo direito que se esgote o mais cedo possível a fonte de vícios, da miséria e dos crimes (... ) a causa desses males esta na ignorância e na falta de educação dos indivíduos.17

\footnotetext{
${ }^{16} \mathrm{El}$ hombre es un yo individual, a cuyo encargo está la administración y uso de su capital, la direción de sus acciones y la práctica de la ocupacion. Pero, como el produto del capital, el móvil de las acciones y el genero de la ocupación no son unos mismos (...) se hace preciso otro yo que abarque y encauce todas estas actividades y que nos represente a todos poniendo así mas de relieve la unidad en esa gran variedad (...) Este és el yo social: El Estado, esta és su missión y en el están comprendidos los poderes que nosotros, general y particularmente, en uso de nuestra soberanía le otorgamos. Si es cierto que este es el verdadero concepto de la entidad Ilamada Estado es evidente que a el le corresponde la obligación de prover a la educación y instrucción del pueblo, asegurando asi el cumplimiento de un derecho, justamente reclamado por a sociedad. NAVARRO, José Gil. Segundo Congreso Americano del Niño, Secção Ensenanza, tomo 7,1919, Montevideo, p. 53.

${ }^{17}$ (... )no es solo el interés del niño el que está aquí en juego, lo está el interés de la sociedad, que exige con todo derecho que se agote o cuanto antes la fuente de los vicios, de la miseria y dos crimes (...) la causa de estos males está en la ignorancia y en la falta de educación de los individuos. Idem
} 
Este clamor à exigência da escolaridade, ou nas palavras de NUNES NETO, ao “direito à obrigação” (2011, p. 170), estará pulverizado em vários trabalhos nos primeiros Congresos Americanos del Niño, por vezes de maneira um tanto autoritária e peremptória, como nas conclusões do trabalho apresentado por Meira e Sá para o Primeiro Congresso Brasileiro e Proteção à Infância em conjunto com o Terceiro Congresso Americano da Criança:

Cumpre que a instrucção primária seja gratuita e obrigatória, instituindose para isso, escolas aptas e sufficientes, - pois ninguém tem o direito de ser analfabeto, e sobretudo - em uma republica democrática a ignorância é um crime - no exacto dizer de H. Mann. (MEIRA E SÁ, 1922, p. 445) [grifos do original]

Meira e Sá, ao propor uma espécie de criminalização da ignorância cita Horace Mann, advogado e educador norte americano que na primeira metade do século XIX propagava a escola pública como único caminho para a civilização e destacava, dentre os seis princípios que elaborou para a educação em seu país que não poderia haver um cidadão livre e ignorante ao mesmo tempo. A ignorância, o analfabetismo, seriam um mal a ser dissipado pela ação forte do Estado. ${ }^{18}$

Neste contexto a escolarização, sobretudo primária, era concebida como a mais eficaz forma de oferecer a complexidade de saberes, modelos e atitudes às crianças e através delas impulsionar a obra regeneradora da população. Instruir e educar, transmitir saberes e em igual medida introjetar comportamentos, esta seria a tarefa da escola que educa e instrui, dentro de um projeto maior de nação. A temática educativa será, por conseguinte, importante centro de atenção nestes primeiros congressos americanos da criança que se ocupam de pensar não apenas o bem estar, mas também o governo da infância.

\footnotetext{
18 “El compromiso de Mann por la educación pública se desprende de su convicción de que la estabilidad política y la armonía social dependen de la educación: un nivel básico de alfabetización y la inculcación de ideales públicos comunes.(...) Los Seis Principios de la Educación de Horace Mann son: 1.Los ciudadanos no pueden ser ignorantes y al mismo tiempo libres; 2.La educación debe ser pagada, controlada y mantenida por el sector público; 3.La educación debe ser impartida en escuelas que reciban niños de todos los orígenes y sectores; 4.La educación no debe ser sectaria; 5.La educación debe ser impartida usando los principios de una sociedad libre; 6.La educación debe ser impartida por docentes profesionales y bien entrenados." Fundación Sarmiento - Mann, on line: http://www.sarmientomann.org/biografia-mann-es.html
} 
Os debates nos congressos circularão em terreno movediço, no qual, concomitantemente, se ratifica a circulação de ideias pedagógicas modernas de matriz europeia (principalmente com raiz nos estudos de Pestalozzi e Montessori), enquanto se esgarçam alguns laços de admiração para com a tradição cultural europeia.

Da mesma forma, grande parte destes projetos buscam criar novos laços pela via de um ensino "prático" que levasse à preparação para o mundo do trabalho muito mais que à erudição. Neste debate de propostas metodológicas e de organização escolar, perceberemos lutas de representação entre influências europeias e norte-americanas sobre modelos culturais, políticos e educativos para os países americanos. Observemos o que disse Webster E. Browning, delegado dos EUA, na sessão solene de abertura do Segundo Congreso del Niño - Montevideo, 1919:

O homem meramente instruído, ainda que ostente títulos das mais conhecidas universidades do velho e novo mundo e brilhe por suas aptidões, pode chegar a ser um perigo à sociedade que o redeia. (...) Para comprovar esta verdade não teríamos que voltar muitas páginas da história, pois o mundo inteiro ainda geme e sangra por conta da falencia e dos delitos de uma civilização que foi esmeradamente instruída, - se se quer-, mas que carecia de educação, de mente e coração.. ${ }^{19}$

A escola prática e cientificamente planejada será discutida à exaustão em inúmeras teses apresentadas nos três primeiros congressos americanos da criança e os vieses desta educação para a eficiência e para o trabalho se refletirão também nas representações de criança que engendram: a criança ativa, mas não irrequieta, a criança inteligente, mas obediente, a criança econômica, limpa, trabalhadora, organizada e a um passo de assumir seu papel de condutora da América a dias cada vez melhores.

A escola idealizada estaria assim empenhada no projeto de civilização da criança americana, configurando a infância, moldando suas aptidões e produzindo o trabalhador necessário para o momento continental que pedia frentes de trabalho cada vez mais

\footnotetext{
${ }^{19}$ El hombre meramente instruido, aunque ostente títulos de las más reconocidas universidades del viejo e del nuevo mundo, y brille por sus aptitudes portentosas, puede llegar a ser un peligro para la sociedad que lo rodea. (...) Para comprobar esta verdad, no tendríamos que dar vuelta a muchas páginas de la historia, pues el mundo enterró aún gime e sangra a causa de la bancarrota y los delitos de una civilización que fue esmeradamente instruida, - si se quiere- mas carecía de educación, de mente e corazón. (BROWNING, Webster E. Segundo Congreso Americano del Nino. 1919, Montevideo, p. 115.)
} 
produtivas e afinadas às necessidades de desenvolvimento que o período favorecia. Vejamos o que diz Julio Picarel, diretor de uma escola Agentina, sobre as habilidades a serem forjadas pela escola:

A humanidade precisa certamente do homem inteligente; mas com mais urgência exige o homem trabalhador. Pensamos muito, trabalhamos pouco (...) Em consequencia: a criança, ao concluir o ciclo completo do primário deve conhecer e aplicar, além do martelo, as tenazes, serras, etc. (...) No momento extraordinário que o mundo atravessa hoje, a mais profunda aspiração universal, e que poderia ser expressa da seguinte forma: escola primária antes de crianças sábias deve ser consagrada a entregar para a sociedade a maior quantidade de crianças boas. Educar antes de instruir, hábitos, em vez de idéias. Ela há de ensinar a usar a virtude e o saber para conquistar a paz através do trabalho. ${ }^{20}$ (grifos do autor)

O texto do Diretor Picarel possibilita que, além da leitura, analisemos no seu conteúdo recursos gráficos que exortam as ideias que lhe são mais caras. À escola básica a missão mais central seria a da educação, entendida aqui como "o repertório de hábitos e atitudes relacionados aos comportamentos que o aluno/criança deveria incorporar" (SOUZA e Hoeller, 2007, p. 196), em detrimento da instrução vinculada aos conteúdos intelectuais e culturais privilegiados em algumas tradições escolares neste contexto associadas ao enciclopedismo e educação elitista e vazia. Educar para o trabalho, para a concórdia, para higiene e moralidade. O destino desejado às crianças/alunas estava de certa forma traçado nos planos de Picarel e de muitos de seus contemporâneos.

A escola, então, estaria afinada às demandas de seu contexto e a perspectiva de formar o cidadão latino americano operoso, limpo, trabalhador, através da difusão da educação pública, que parece estar contemplada em diversos projetos de escolarização dos países americanos e latino americanos no início do séc. XX.

\footnotetext{
${ }^{20}$ La humanidad necesita desde luego del hombre inteligente; pero mas reclama com urgencia al hombre trabajador. Pensamos mucho, trabajamos poco. (...) En consecuencia: El niño, ao completar el ciclo primário integral deberá conocer y aplicar, ademas del martillo, las tenazes, las sierras, etc. (...) en la hora extraordinaria porque atraviesa el mundo en la actualidad, la mas profunda aspiración universal , y que se podría concretarse así: la escuela primaria, antes que niños sábios, ha de se consagrarse a entregar a la sociedad la mayor cantidad de niños buenos. Educar antes de instruir, hábitos más que ideas. Ha de enseñar a usar la virtud y el saber para conquistar la paz por el trabajo. PICAREL, Julio. Segundo Congreso Americano del Niño, Carpeta 3, Tomo Sete, p. 67, 1919.
} 
No entanto, entendemos este fenômeno numa perspectiva não homogeneizante, como aponta Kuhlmann Jr. (2006), considerando as nuances deste movimento de expansão e absorção de um modelo de escolarização em diferentes países como um fenômeno que, embora apresente inegáveis similaridades, não é retilíneo, naturalizado e independente. A difusão internacional de princípios e modelos educativos está imersa numa lógica mais ampla que envolve a cultura, a economia, a política, as relações diplomáticas e que são "elementos constitutivos das relações sociais" dentro das quais se produzem (KUHLMANN JR., 2006, p. 8).

Não há como isolar a expansão da escolarização dos demais fenômenos sociais portanto. Tampouco, são válidas as cristalizações de perspectivas de análise sobre os motores deste processo dada a amplitude das transformações e adaptações exigidas a todos neste torvelinho que configurou o processo de modernização da América Latina no início do século XX. A análise dos documentos produzidos nos Congresos Americanos del Niño traz a oportunidade de nos depararmos com pequenos detalhes, com nuances que podem ampliar as possibilidades de reflexão sobre este momento na história da infância americana.

Afirmar modelos de infância e parâmetros para a formação escolar é uma das vertentes do projeto de definição de uma difusamente almejada cidadania intracontinental. Assim, por um lado serão expostas as bases da educação e cuidados com a infância, enquanto, paralelamente, ações de teor diplomático e cívico serão exortadas, tais como congressistas propondo votos pela “Confraternização Americana”21 ou a criação de um "hino à raça latino-americana",22, propostas da obrigatoriedade do ensino dos Hinos Nacionais de todos os países americanos em todas as escolas do continente $e^{23}$, entre outras.

\footnotetext{
${ }^{21}$ Proposto por G,. Ruiz, delegado Salvadorense no Terceiro Congresso Americano da Criança, Rio de Janeiro, 1922. Tomo 1, Votos, Secção de Pedagogia, p. 131. Imprensa Nacional, 1924.

${ }^{22}$ Proposto por Benito Soria, chileno. Terceiro Congresso Americano da Criança, Rio de Janeiro, 1922. Tomo 1, Votos, Secção de Pedagogia, p. 131. Imprensa Nacional, 1924.

23 Proposto por Virgilio Cutinella, uruguaio.Segundo Congreso Americano del Niño, Tomo Oito, 1919, Montevideo, p. 24.
} 
Perceberemos que muitas palestras discutem a criança nos termos de "El niño Americano" como se este fosse uno e capaz de condensar a unidade e o ideal de homem americano em um futuro próximo.

\section{Referências}

AIZCORBE, Cesar Sánchez. Discurso do delegado do Peru Dr. Cesar Sánchez Aizcorbe na Sessão Solene Inaugural em 18 de Maio de 1919. Segundo Congreso Americano del Niño. Tomo I, Montevideo: : PeñoHmos. Impresores, 1919, p.125-128.

ANALES de Instrucción Primária, Ano XIV - Tomo XIV - n 1-6, Montevideo: Imprenta El Siglo, 1916. Ilustrado.

BENJAMIN, Walter. Paris capital do século XIX. In: KOTHE, Flávio (Org).Walter Benjamin. São Paulo: Ática, 1995. P.30-43.

CARLI, Sandra. Niñez, pedagogia e política: transformaciones de los discursos acerca de la infância em la historia de la educacion argentina entre 1880 e 1955. Buenos Aires: Miño y Dávila, 2003.

CHARTIER, Roger. O mundo como representação. Estudos Avançados: Instituto de Estudos Avançados - USP, São Paulo, v. 5, n. 11, 1991.

COMITÉ NACIONAL BRAZILEIRO DO PRIMERO CONGRESSO AMERICANO DA CREANÇA. $3^{\circ}$ Boletim, maio e junho de 1916. Rio de Janeiro: Imprensa Nacional. 1916.

COMITÉ NACIONAL BRAZILEIRO DO PRIMERO CONGRESSO AMERICANO DA CREANÇA. $4^{\circ}$ Boletim, julho a agosto de 1916. Rio de Janeiro: Imprensa Nacional. 1917. 503p.

CONGRESO AMERICANO DEL NIÑO, 2, mayo de 1919, Montevideo. Antecedentes y organización; programas; sesionesplenarias; visitas; excursiones; votos aprobadosenplenarios. Tomo I. Montevideo: PeñoHmos. Impresores, 1919a. 266 p.

CONGRESO AMERICANO DEL NIÑO, 2, mayo de 1919, Montevideo. Actas y trabajos de lasección de Higiene y Asistencia. $1^{\mathrm{a}}, 2^{\mathrm{a}}, 3^{\mathrm{a}}$, Plenaria y 4 Sesiones. Tomo IV. Montevideo: PeñoHmos. Impresores, 1920. 651p.

CONGRESO AMERICANO DEL NIÑO, 2, mayo de 1919, Montevideo. Compilación de documentos Enseñanza, Carpeta III. Montevideo: mimeo, 1919. 293p. 
CONGRESO AMERICANO DEL NIÑO, 2, mayo de 1919, Montevideo. Compilación de documentos Enseñanza, Carpeta V. Montevideo: mimeo, 1919. 168p.

CONGRESO AMERICANO DEL NIÑO, 2, mayo de 1919, Montevideo. Compilación de documentos Enseñanza, Carpeta VIII. Montevideo: mimeo, 1919. 187p.

CONGRESO AMERICANO DEL NIÑO, 2, mayo de 1919, Montevideo. Compilación de documentos Sociología y Legislación, Carpeta IX. Montevideo: mimeo, 1919. 28op.

CONGRESO AMERICANO DEL NIÑO, 2, mayo de 1919, Montevideo. Compilación de documentos Sociología y Legislación, Carpeta X. Montevideo: mimeo, 1919. 156p.

FARGE, Arlete. Lugares para a história. Belo Horizonte: Autêntica, 2011.

GEREMEK, Bronislaw. Le radici comuni dell'Europa. A cura di Francesco M. Cataluccio. Milano: II Saggiatore, 1991.

HOBSBAWM, Eric. A era dos impérios. Rio de Janeiro: Paz e Terra, 1988.

KUHLMANN JR., Moysés. As grandes festas didáticas: a educação brasileira e as exposições internacionais (1862-1922). Bragança Paulista: Editora da Universidade São Francisco, 2001.

KUHLMANN JR., Moysés. História da educação, comparação e classificação. In: CONGRESSO LUSO-BRASILEIRO DE HISTÓRIA DA EDUCAÇÃO, VI, 2006, Uberlândia.

Anais... do VI Congresso Luso-Brasileiro de História da Educação: percursos e desafios da pesquisa e do ensino de história da educação. Uberlândia, 2006. v. 1, p. 6429-6438. Disponível em http:

<//www.faced.ufu.br/colubhe06/anais/arquivos/581KuhlmannAtual.pdf >. Acesso em....

LA VANGUARDIA, órgão de comunicação do Partido Socialista Argentino, março de 1913 e julho de 1916, Buenos Aires.

MEIRA E SÁ, Francisco de Sales. "Do problema capital, urgente, inadiável do Brasil nas suas duas faces". Terceiro Congresso Americano da criança e Primeiro Congresso Brasileiro de Proteção à Infância. $7^{\circ}$ Boletim, Rio de Janeiro, Imprensa Nacional, 1924, p. 434-445.

MORQUIO, Luis. Discurso del Presidente del Congreso Dr. Luis Morquio na Sessão Solene Inaugural em 18 de Maio de 1919. Segundo Congreso Americano del Niño. Tomo I, Montevideo: PeñoHmos. Impresores, 1919, p. 75-94.

MOTTA, Marly Silva da. A nação faz cem anos: a questão nacional no centenário da independência. Rio de Janeiro: Editora FGV: CPDOC, 1992. 129 p. 
NUNES, Eduardo Netto. A Infância como portadora do futuro na América Latina: 19161948. 2011, 00 f. Tese (Doutorado em História Social) - Universidade de São Paulo, São Paulo, 2011.

OSSENBACH, Gabriela. Estado y Educación en América Latina a partir de su independencia (siglos XIX y XX). Revista Iberoamericana de Educación , n.1 1, Enero/Abril 1993.

Dispovível em: < http://www.rieoei.org/oeivirt/rie01a04.htm> . Acesso em 23 de janeiro.

PAZ SOLDAN, Carlos Enrique. Los Niños. Lima: Ediciones La Reforma Medica, 1944. 483 p.

PESAVENTO, Sandra Jatahy. Nós e Os Outros: As Exposições Universais e o Imaginário Europeu sobre a América. In: Bessoni, Tânia Maria Tavares.; Queiroz, Tereza Aline de (Orgs.). América Latina: Imagens, Imaginação e Imaginário. Rio de Janeiro: Expressão e Cultura; São Paulo: EDUSP, 1997.

PESAVENTO, Sandra Jatahy. História \& história cultural. Belo Horizonte: Autêntica, 2004 .

PRIMER CONGRESSO AMERICANO DE NIÑO, $4^{\circ}$ boletin, Imp. Escoffier, Caracciolo y cia, Buenos Aires, 1916.

PRIMER CONGRESSO NACIONAL DEL NIÑO, Conclusiones, Imp. Escoffier, Caracciolo y cia, Buenos aires,1913.

RIZZINI, Irene. Reflexões sobre pesquisa histórica com base em idéias e práticas sobre a assistência à infância no Brasil na passagem do século XIX para o XX.. In: I CONGRESSO INTERNACIONAL DE PEDAGOGIA SOCIAL, 1., 2006, . Proceedings online... Faculdade de Educação, Universidade de São Paulo, Available from:

<http://www.proceedings.scielo.br/scielo.php?script=sci_arttext\&pid=MSC00000000920 06000100019\&lng=en\&nrm=abn>. Acesso on: $27 \mathrm{Abr} ; .2015$.

ROUSSEAU, Jean Jacques. Emílio ou da educação. São Paulo: Difel, 1979.

SOBRAL, Francisco Fernandes. Terceiro Congresso Americano da Criança e Primeiro Congresso Brasileiro de Proteção à Infância. $7^{\circ}$ Boletim, Rio de Janeiro, Imprensa Nacional, 1924, p. 304.

SOUZA, Gizele de \& HOELLER, Solange. Instrução e educação higiênica da infância catarinense na Primeira República (1910-1930). Roteiro, Joaçaba, v. 32, n. 2, p. 183-200, jul./dez. 2007. 
Recebido em 28/02/2015 Aprovado em 29/03/2015

Universidade do Estado de Santa Catarina - UDESC Programa de Pós-Graduação em História - PPGH Revista Tempo e Argumento Volume 07 - Número 14 - Ano 2015 tempoeargumento@gmail.com 